\section{Competition for cofactor- dependent DNA binding underlies Hox phenotypic suppression}

\author{
Barbara Noro, ${ }^{1,4}$ Katherine Lelli, ${ }^{2,4}$ Liping Sun, ${ }^{3}$ \\ and Richard S. Mann ${ }^{3,5}$ \\ ${ }^{1}$ Department of Neuroscience, ${ }^{2}$ Department of Genetics \\ and Development, ${ }^{3}$ Department of Biochemistry and Molecular \\ Biophysics, College of Physicians and Surgeons, Columbia \\ University, New York, New York 10032, USA
}

Hox transcription factors exhibit an evolutionarily conserved functional hierarchy, termed phenotypic suppression, in which the activity of posterior Hox proteins dominates over more anterior Hox proteins. Using directly regulated Hox targeted reporter genes in Drosophila, we show that posterior Hox proteins suppress the activities of anterior ones by competing for cofactor-dependent DNA binding. Furthermore, we map a motif in the posterior Hox protein Abdominal-A (AbdA) that is required for phenotypic suppression and facilitates cooperative DNA binding with the Hox cofactor Extradenticle (Exd). Together, these results suggest that Hox-specific motifs endow posterior Hox proteins with the ability to dominate over more anterior ones via a cofactor-dependent DNA-binding mechanism.

Supplemental material is available for this article.

Received July 25, 2011; revised version accepted October 7, 2011.

The Hox or homeotic genes encode a conserved set of homeodomain-containing transcription factors that control morphological identities along the anterior-posterior (AP) axes in both vertebrates and invertebrates. Although this Hox gene function is conserved across phyla, more recently, these genes have been shown to play additional roles in animal development, from motor neuron identity determination to stem cell maintenance (Ernst et al. 2004; Dasen and Jessell 2009).

One of the hallmarks of the Hox gene family is that individual members are expressed at specific AP positions in the developing embryo. Hox expression patterns are collinear with their positions along the chromosome: Hox factors that are expressed anteriorly are located 3 ' to more posteriorly expressed Hox genes. Hox genes are typically clustered in metazoans; in mice and humans, 39 Hox genes reside in one of four Hox complexes, while in Drosophila melanogaster, eight genes reside in two complexes. The more anteriorly expressed Antennapedia complex includes labial (lab), proboscipedia $(p b)$, Deformed (Dfd), Sex combs

[Keywords: DNA binding; Drosophila; Exd/Pbx; Hox genes; post-translational regulation]

${ }^{4}$ These authors contributed equally to this work.

${ }^{5}$ Corresponding author.

E-mail rsm10@columbia.edu.

Article is online at http://www.genesdev.org/cgi/doi/10.1101/gad.175539.111. reduced $(S c r)$, and Antennapedia $(A n t p)$, which establish the identities of parasegments 1-5 (PS1-PS5); the Bithorax complex codes for the most posteriorly expressed abdominal Hox genes Ultrabithorax $(U b x), A b d o m i n a l-A(A b d A)$, and $A b d o m i n a l-B(A b d B)$, required for PS6-PS14 identities (Hughes and Kaufman 2002).

The collinear distribution of Hox genes also correlates with the ability of posterior family members to functionally dominate over more anterior ones via post-transcriptional cross-regulatory interactions. This phenomenon, known as phenotypic suppression or posterior dominance, was first recognized by analyzing mutants of the Polycomb group of genes (Struhl 1983) and from experiments in which Hox proteins were misexpressed during Drosophila embryogenesis. It was noticed that posterior segments were generally not transformed, even when more anterior Hox proteins were ubiquitously expressed at high levels. For example, ubiquitous expression of Ubx, which normally establishes the PS6 identity, transformed all thoracic and head segments toward this identity (Gonzalez-Reyes and Morata 1990, 1991; Mann and Hogness 1990). However, Ubx was unable to transform abdominal segments toward PS6. Similarly, ubiquitous Antp could efficiently transform segments anterior to PS4, where it is normally active, but was unable to transform more posterior regions (Schneuwly et al. 1987; Gibson et al. 1990). Analogous observations have been made in vertebrates, suggesting that this phenomenon is evolutionarily conserved (Bachiller et al. 1994; Duboule and Morata 1994). However, the molecular mechanisms responsible for phenotypic suppression are poorly understood.

Several mechanisms have been invoked to account for phenotypic suppression. One way in which posterior Hox factors dominate over anterior Hox proteins is that the former are, in general, transcriptional repressors of the latter; for example, Ubx is a repressor of Antp (Hafen et al. 1984; Harding et al. 1985; Struhl and White 1985; Carroll et al. 1986). Post-transcriptional regulation of Hox expression by microRNAs (miRs) has also been postulated to partly underlie phenotypic suppression (Chopra and Mishra 2006; Singh and Mishra 2008; Yekta et al. 2008). According to this model, miRs that target anterior Hox genes are expressed in more posterior segments, and thus would be available to suppress anterior Hox gene functions. Consistent with this idea, miRs that are predicted to target more anterior Hox genes are often located $5^{\prime}$ to that Hox gene and, due to collinearity, would be expected to be expressed in more posterior domains. Furthermore, several Drosophila miRs have been identified that have the predicted ability to suppress more anterior Hox gene functions when ectopically expressed (Ronshaugen et al. 2005).

However, these mechanisms cannot fully explain phenotypic suppression, which functions, at least in part, at the post-translational level. For example, when either Ubx or Antp is expressed ubiquitously, they fail to transform abdominal segments despite high levels of expression in all embryonic cells (Gonzalez-Reyes et al. 1990; Mann and Hogness 1990); the abdominal Hox factors AbdA and AbdB post-translationally block Ubx and Antp functions in these segments. Moreover, when Ubx and Antp are forced to be coexpressed in all embryonic cells, anterior segments are transformed toward PS6, not PS4, demonstrating that the activity of Antp is suppressed in a post-translational manner 
by Ubx (Gonzalez-Reyes et al. 1990). In general, the transgenes used to express these Hox proteins do not contain the native Hox gene $3^{\prime}$ untranslated regions (UTRs) that are typically targeted by miRs. Moreover, mutants that delete Bithorax complex miRs do not display any of the homeotic transformations that would be expected if posterior dominance were compromised (Bender 2008). Together, these observations suggest that other post-translational mechanisms are at play.

Here we test two alternative models that can account for the post-translational nature of phenotypic suppression. Hox DNA-binding affinity and specificity are often enhanced by cooperatively binding with cofactors, such as the homeodomain proteins Extradenticle (Exd) in Drosophila and Pbx in vertebrates (Moens and Selleri 2006; Mann et al. 2009). This raises the possibility that competition for cofactors-either on or off DNA - could underlie phenotypic suppression. To test these models, we developed an in vivo assay for phenotypic suppression using two Hox factors that have distinct activities: Scr, an anterior Hox protein, and AbdA, a posterior Hox protein. Using two well-defined reporter genes that are dependent on HoxExd-binding sites for their regulation, we show that AbdA can only suppress Scr's activity when it can compete for DNA binding in a cofactor-dependent manner. In addition, we identified an evolutionarily conserved sequence motif in AbdA that enables cooperative complex formation with Exd and is required for AbdA's ability to dominate over anterior Hox proteins. Together, these results suggest that phenotypic suppression occurs when anterior and posterior Hox proteins compete for the same binding sites in shared target genes. In such cases, the unique molecular architecture of posterior Hox factors results in a higher affinity for these targets, thus imposing their functions even in the presence of anterior Hox factors.

\section{Results and Discussion}

fkh250 is a 37-base-pair (bp) element from the forkhead (fkh) gene, which is directly regulated by Scr; it contains a single Hox-Exd-binding site that, compared with other Hox-Exd heterodimers, is preferentially bound by Scr-Exd in vitro (Ryoo and Mann 1999). When lacZ is placed under the control of fkh250, fkh250-lac $Z$ is specifically expressed in PS2 in an exd-and Scr-dependent manner (Ryoo and Mann 1999). Indeed, misexpression of Scr throughout the Drosophila embryo can ectopically activate fkh250-1acZ (Fig. 1A; Ryoo and Mann 1999; Joshi et al. 2007, 2010). Notably, ectopic activation of $f k h 250-1 a c Z$ occurs even in the abdomen, in the presence of endogenous, more posterior Hox.

In contrast to fkh250, fkh250 CON (for "consensus") is an artificial variant of $f k h 250$ with two base pair substitutions that enable $f k h 250^{C O N}-1 a c Z$ to be directly regulated by four Hox genes in an exd-dependent manner: Scr, Antp, and $U b x$ activate this reporter in PS2-PS6, while AbdA represses it in abdominal segments (Fig. 1A; Ryoo and Mann 1999). Consistent with its relaxed specificity in vivo, $f k h 250^{C O N}$ binds well to Scr-Exd, Antp-Exd, Ubx-Exd, and AbdA-Exd heterodimers in vitro (Ryoo and Mann 1999). The promiscuous binding and regulation by multiple Hox proteins classifies $f k h 250^{C O N}$ as a shared Hox target gene, while the Scr-specific regulation of and binding to fkh250 suggests that it is a specific Hox target gene (Mann et al. 2009).

Because of their distinct specificities, fkh250-1acZ and $f k h 250^{C O N}$-lac $Z$ provide an ideal system to examine the

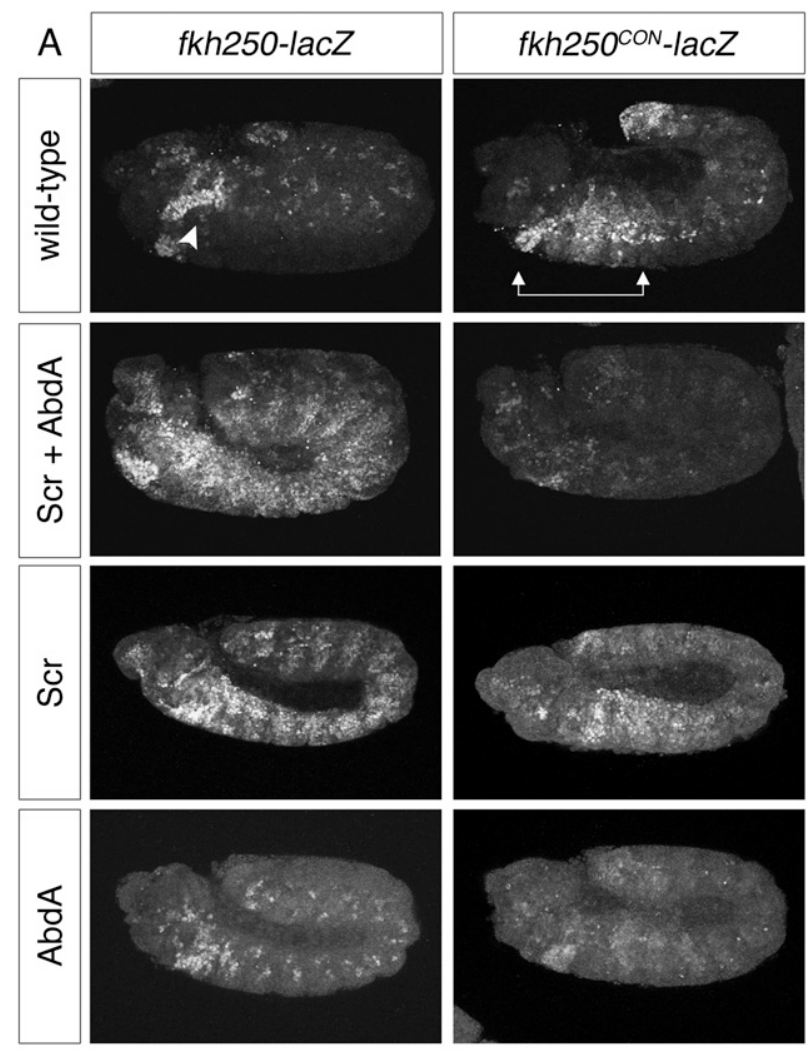

B
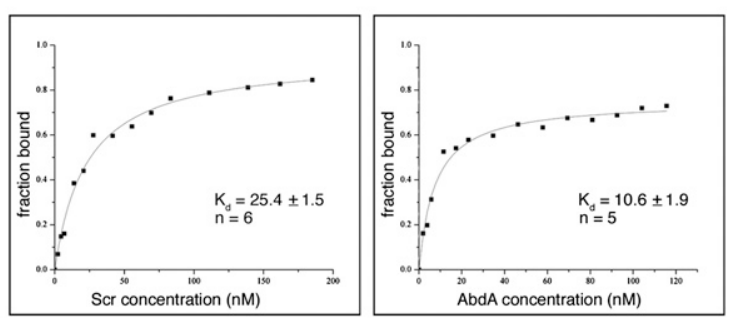

Figure 1. AbdA dominance over Scr relies on an Exd-dependent DNA-binding mechanism. (A) Embryos carrying fkh250-lacZ (left panels) or $f$ kh250 ${ }^{C O N}$-lacZ (right panels) stained for $\beta$-galactosidase ( $\beta$-gal). In wild-type embryos, endogenous Scr activates fkh250-lac $Z$ in PS2 (arrowhead), while fkh250CON -lacZ is activated by Scr, Antp, and Ubx from PS2 to PS6 (arrows) and is repressed by AbdA in the abdominal segments. Ectopic expression of Scr throughout the embryo, alone or in combination with AbdA, results in widespread activation of fkh250-lacZ. In contrast, fkh250 ${ }^{C O} N_{-}-$lacZ is repressed when Scr and AbdA are both ectopically expressed. $(B)$ Representative in vitro saturation binding experiments and dissociation constant $\left(K_{\mathrm{d}}\right.$ in nanomolar) fits are shown for Scr-Exd (left) and AbdA-Exd (right) binding to $f k h 250^{C O N}$. AbdA-Exd dimers bound more tightly to $f k h 250^{C O N}$ than Scr-Exd did, supporting a model in which AbdA dominance depends on cofactor-dependent DNA binding. All assays were performed in the presence of Exd-Hth ${ }^{\mathrm{HM}}$. The reported $K_{\mathrm{d}} \mathrm{s}$ represent the averages and standard error of the means of repeated measurements $(n=5$ for AbdA, and $n=6$ for Scr) (see the Materials and Methods).

molecular mechanism of phenotypic suppression. In accordance with the premise of posterior dominance, coexpression of Scr and AbdA throughout the fly embryo leads to repression of $f k h 250^{C O N}-1 a c Z$ by AbdA (Fig. 1A). In contrast, fkh250-lac $Z$ is robustly activated by Scr even in the presence of AbdA (Fig. 1A). Note that both $f k h 250$ and $f k h 250^{C O N}-1 a c Z$ require direct binding by the Hox cofactor Exd (Ryoo and Mann 1999). The primary distinction 
between these two readouts is that AbdA-Exd binds well to $f k h 250^{C O N}$ but not to $f k h 250$. Accordingly, we conclude that AbdA cannot suppress the activities of Scr if it cannot bind to the target element. Furthermore, in this system, posterior dominance cannot be mediated by miR activity or competition for factors, such as Exd, off DNA. Rather, these data support a model in which competition for
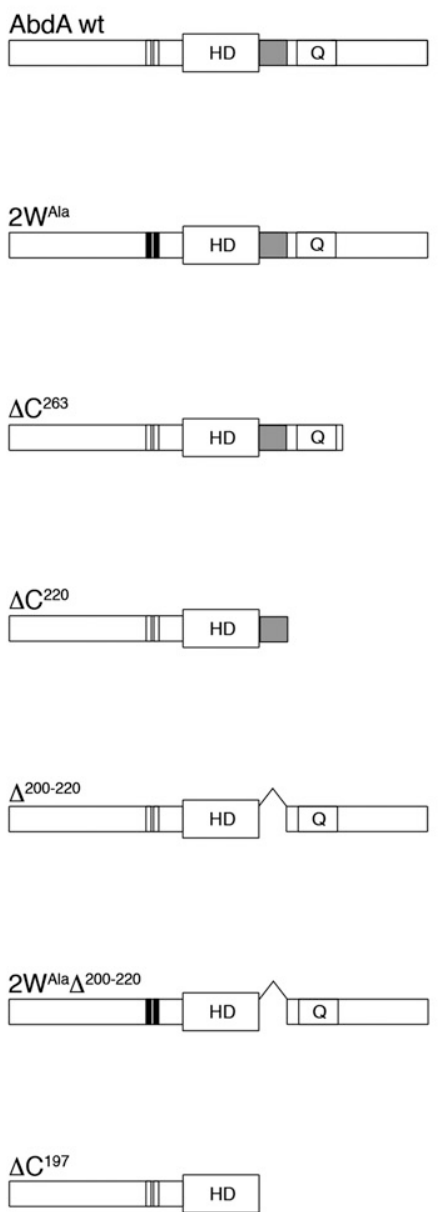
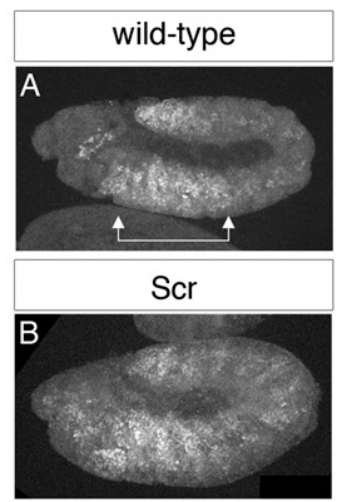

$\mathrm{Scr}+\mathrm{AbdA}^{\mathrm{mut}}$
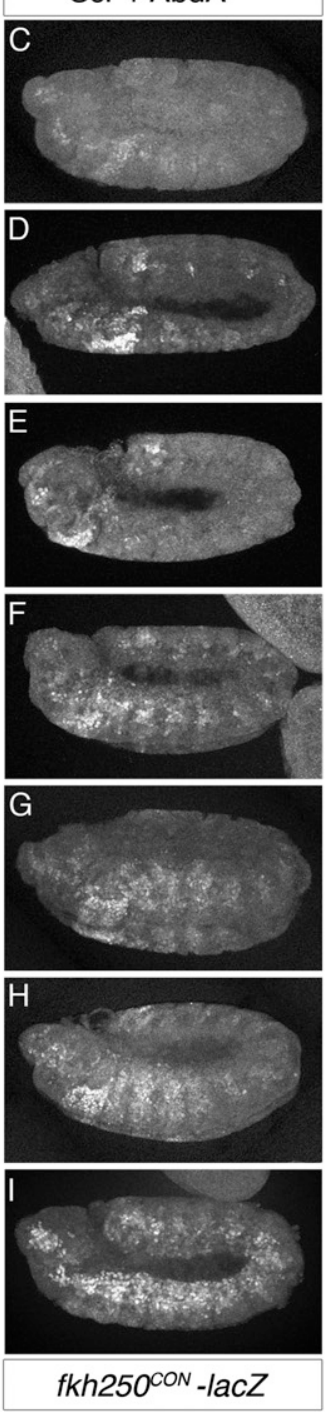

cofactor-dependent DNA binding underlies phenotypic suppression for shared Hox target genes.

If $\mathrm{AbdA}$ is outcompeting Scr for binding to $f k h 250^{C O N}$ AbdA would be expected to have a higher affinity for this sequence compared with Scr. To test this prediction, we measured the affinities of AbdA-Exd and Scr-Exd heterodimers for $f k h 250^{C O N}$ in vitro. AbdA-Exd heterodimers bound more than twofold more tightly to fkh250 CON compared with Scr-Exd (with dissociation constants $\left[K_{\mathrm{d}}\right]$ of $10.6 \pm 1.9 \mathrm{nM}$ and $25.4 \pm 1.5 \mathrm{nM}$, respectively) (Fig 1B). Thus, at the same concentration, AbdA-Exd is more likely than Scr-Exd to be bound to $f k h 250^{C O N}$, consistent with the idea that competition depends on cofactor-dependent DNA binding.

Binding to $f k h 250^{C O N}$ is Exd-dependent for both AbdA and Scr (Ryoo and Mann 1999), implying that AbdA has domains that allow higher binding affinity with Exd to this target site. In general, Hox interactions with Exd are mediated by the highly conserved, four-amino-acid motif YPWM, which directly binds to a hydrophobic pocket established by the three-amino-acid loop extension (TALE) in the Exd homeodomain (Mann et al. 2009). For some Hox proteins, the YPWM-TALE interaction is necessary and sufficient for cooperative DNA binding with Exd and target gene regulation in vivo (Joshi et al. 2010). In addition to the YPWM motif, AbdA, but not Scr, has a second wellconserved tryptophan-containing motif, TDWM, which could play a role in mediating AbdA-Exd interactions (Supplemental Fig. 1). However, when a mutant form of AbdA in which both the YPWM and TDWM motifs are mutated to alanines (2W Ala $)$ was coexpressed with Scr in our phenotypic suppression assay, fkh250 ${ }^{C O N}$-lacZ was repressed to the same extent as by wild-type AbdA (Fig. 2C,D). Thus, although the YPWM and TDWM may contribute to interactions with Exd, these motifs are not necessary for AbdA to dominate over Scr.

Immediately C-terminal to its homeodomain, AbdA contains a so-called UbdA motif, a nine-amino-acid sequence also present in Ubx, which has been suggested to mediate cooperative binding with Exd to some DNA

Figure 2. AbdA dominance over Scr depends on its C-terminal UR motif. (A) Wild-type expression of $f k h 250^{C O N}$-lacZ (stained for $\beta$-gal). (B) fkh250CON-lacZ activation in the context of ubiquitous expression of Scr. AbdA variants $\left(\mathrm{AbdA}^{\mathrm{mut}}\right.$ ) (diagrammed at left) were ectopically expressed in combination with Scr to define motifs in AbdA necessary to suppress Scr activation of $f k h 250^{C O N}$-lacZ (stained for $\beta$-gal) (right). Shown are representative images for each AbdA variant, which are ordered according to their ability to repress fkh250CON-lacZ from strongest (C, wild-type AbdA) to weakest (I, no $C$ terminus: $\left.\Delta C^{197}\right)$. $(D, E)$ Wild-type-repressive activity was observed for an AbdA variant in which the YPWM and TDWM motifs were mutated to alanines $\left(2 \mathrm{~W}^{\mathrm{Ala}}\right)$, or when part of the $\mathrm{C}$ terminus was deleted $\left(\Delta C^{263}\right)$, suggesting that these motifs are not necessary for repression of this target. (I) Deletion of the entire C-tail of AbdA $\left(\Delta \mathrm{C}^{197}\right)$ abolishes repression of fkh250 $0^{C O N}$-lacZ. (F) Repression is significantly rescued by the addition of the UR motif adjacent to the homeodomain $(\mathrm{HD})\left(\Delta \mathrm{C}^{220}\right)$. (G) Consistently, an internal deletion of $\mathrm{UR}\left(\Delta^{200-220}\right)$ partially impairs AbdA's ability to suppress activation of $f k h 250^{C O N}$-lacZ by Scr. (H) A variant in which both the YPWM and TDWM motifs are mutated in combination with this internal deletion $\left(2 \mathrm{~W}^{\mathrm{Ala}} \Delta^{200-220}\right)$ displayed no additional loss of repressive ability, suggesting that the UR motif of AbdA is critical for posterior dominance. In the schematics of the AbdA variants, the $\mathrm{N}$-terminal YPWM and TDWM motifs are indicated by white bars (colored black when mutated to alanines), the $\mathrm{HD}$ is indicated, the C-terminal UR motif is in grey, and Q indicates a glutamine-rich region. 
sequences (Merabet et al. 2007). In fact, UbdA is part of a larger 23-residue conserved region adjacent to the AbdA homeodomain, which we refer to here as the UR motif (for UbdA-RRDR) (Supplemental Fig. 1). To determine whether this or other regions in the C-tail of AbdA are involved in mediating phenotypic suppression, we tested a series of C-terminal truncations for their ability to compete with Scr for the repression of $f k h 250^{C O N}-$ lac $Z$ in vivo. All AbdA variants were epitope-tagged, allowing us to use transgenes that express at similar levels (Supplemental Fig. 2).

AbdA's ability to compete with Scr for fkh250 CON regulation is eliminated when the entire $\mathrm{C}$ terminus is removed $\left(\Delta \mathrm{C}^{197}\right)$ (Fig. 2I). Adding back only the UR motif partially restores AbdA's ability to dominate over Scr $\left(\Delta \mathrm{C}^{220}\right)$ (Fig. 2F). Consistently, an internal deletion that removes most of the UR motif $\left(\Delta^{200-220}\right)$ (Fig. 2G) exhibits a reduced ability to repress $f k h 250^{C O N}-l a c Z$. No additional loss of repressive activity is displayed by an AbdA variant in which both the YPWM and TDWM motifs are mutated in combination with this internal deletion $\left(2 \mathrm{~W}^{\mathrm{Ala}} \Delta^{200-220}\right)$ (Fig. 2H). Additional sequences in the C-tail of AbdA may account for the residual activity of variants lacking the UR motif $\left(\Delta^{200-220}\right.$ and $\left.2 \mathrm{~W}^{\mathrm{Ala} a} \Delta^{200-220}\right)$ (Fig. 2G,H). All AbdA variants used in this study are capable of repressing the exd-independent target gene spalt in the wing imaginal disc (Supplemental Fig. 3), confirming that these mutants are still functional transcription factors. Furthermore, these mutants retain the ability to repress gene expression in vivo, arguing that AbdA's repressive activity is not sufficient to account for its ability to dominate Scr. Together, these data highlight the importance of the UR motif for phenotypic suppression.

The above data show that the UR motif is required for AbdA to compete with Scr in vivo. To test the hypothesis that UR carries out this function by facilitating cooperative DNA binding with Exd, we analyzed the ability of the truncated AbdA variants to bind fkh250CON in complex with Exd (Fig. 3). In general, the results correlate with the in vivo phenotypic suppression assay: Those mutants that failed to suppress Scr's ability to activate $f k h 250^{C O N}-1 a c Z$ $\left(\Delta \mathrm{C}^{197}, \Delta^{200-220}\right.$, and $\left.2 \mathrm{~W}^{\mathrm{Ala}} \Delta^{200-220}\right)$ were severely compromised in binding fkh250 CON with Exd in vitro (Fig. 3). Together, these data strongly suggest that cooperative DNA binding with Exd is required for phenotypic suppression and that domains unique to AbdA are critical for its ability to dominate over Scr. More specifically, they argue that AbdA's UR motif is necessary for cooperative binding of

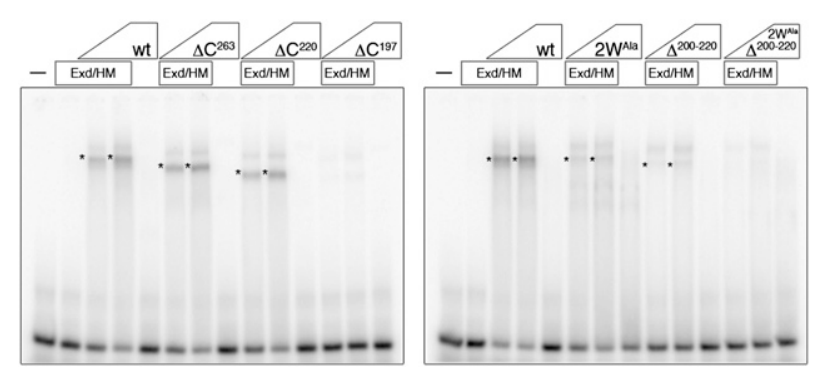

Figure 3. The C-terminal UR motif of AbdA mediates cooperative binding with Exd on $f k h 250^{C O N}$. Variants of AbdA missing the UR motif $\left(\Delta \mathrm{C}^{197}, \Delta^{200-220}\right.$, and $\left.2 \mathrm{~W}^{\mathrm{Ala}} \Delta^{200-220}\right)$ do not form cooperative complexes with Exd on $f k h 250^{C O N}$ in vitro, as analyzed by electrophoretic mobility shift assays (EMSAs). Cooperative complexes between AbdA variants and Exd are indicated by asterisks. EMSAs were performed in the presence of Exd-Hth ${ }^{\mathrm{HM}}$ as indicated (see the Materials and Methods).
AbdA and Exd to $f k h 250^{C O N}$ and that the YPWM and TDWM motifs are not sufficient to mediate this interaction on this binding site. The insufficiency of the YPWM motifs to mediate cooperative binding with Exd has been observed for other Hox proteins (Galant et al. 2002; Merabet et al. 2003, 2007; Saadaoui et al. 2011), suggesting that the use of paralog-specific motifs such as UR may be a general phenomenon.

To test the generality of AbdA's dependency on its UR motif for posterior dominance, we analyzed the same AbdA variants for their ability to suppress the activity of the thoracic Hox protein Antp in the patterning of the larval epidermis. When ectopically expressed, Antp transforms the head and first thoracic segment (T1) toward the identity of the second thoracic segment (T2), where Antp is normally expressed (Fig. 4A). In contrast, when AbdA is ectopically expressed, the head and thorax acquire abdominal segmental identities (Fig. 4A). Consistent with the rules of phenotypic suppression, wild-type AbdA is able to produce this transformation even in the presence of exogenous Antp (Fig. 4B). However, similar to the results with fkh250CON-lacZ, AbdA mutants that are compromised in their ability to cooperatively bind DNA with Exd (e.g., $\Delta \mathrm{C}^{197}, \Delta^{200-220}$, and $\left.2 \mathrm{~W}^{\mathrm{Ala}} \Delta^{200-220}\right)$ fail to suppress the activity of Antp (Fig. 4B).

Taken together, these data support a model in which phenotypic suppression depends on a competition for cofactor-dependent DNA binding. It follows that this mechanism would only apply to readouts that depend on regulatory elements that are targeted by multiple Hox proteins. For example, ectopic Scr can activate $f k h$ and other target genes required for salivary gland development in more posterior segments, illustrating that this Hox-specific function does not obey phenotypic suppression (Kuziora and McGinnis 1988; Gibson et al. 1990; Jegalian and De Robertis 1992; this study). Furthermore, it is particularly noteworthy that, compared with the anterior Hox protein Scr, AbdA has additional motifs that facilitate complex formation with Exd on DNA. Our data suggest that when phenotypic suppression is observed, the more posterior Hox proteins may have a higher affinity for shared binding sites; this higher affinity is a consequence of the quantity and quality of motifs that mediate cooperative DNA binding with Exd. We speculate that these motifs may be used differently at different target genes and binding sites. We suggest that the YPWM motif provides a common, basal level of interaction between Hox proteins and Exd. In the context of Hox-specific regulatory elements, this motif may be sufficient to enable Hox-Exd regulation of some target genes (Joshi et al. 2010). In contrast, in the context of shared enhancers and when multiple Hox proteins are coexpressed, additional, paralog-specific motifs present in the more posterior Hox proteins enable tighter binding of Hox-Exd dimers to DNA, leading to more posterior phenotypes. We showed this to be the case for a single shared Hox-Exd enhancer and suggest that the generality of this mechanism for phenotypic suppression will become apparent as more shared and specific targets for Hox proteins are characterized at high resolution.

\section{Materials and methods}

\section{Fly strains and genetic manipulations}

The GAL4/UAS system (Brand and Perrimon 1993) was used to ectopically express UAS-3XHA-Scr (Joshi et al. 2007) and UAS-6XMyc-AbdA 
A

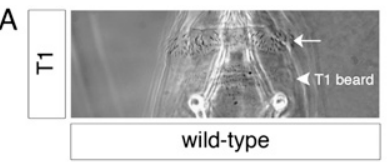

B

\begin{tabular}{ll}
\hline \multicolumn{2}{|c|}{ Antp + AbdA $^{\text {mut }}$} \\
AbdA wt & $102 \%(n=292)$ \\
$2 W^{\text {Ala }}$ & $101 \%(n=226)$ \\
$\Delta C^{263}$ & $107 \%(n=143)$ \\
$\Delta C^{220}$ & $98 \%(n=145)$ \\
$\Delta^{200-220}$ & $40 \%(n=223)$ \\
$2 W^{\text {Ala }} \Delta^{200-220}$ & $2 \%(n=70)$ \\
$\Delta C^{197}$ & $11 \%(n=142)$ \\
& \\
\hline &
\end{tabular}

Figure 4. The UR motif endows AbdA with the ability to dominate over Antp in patterning of the larval epidermis. Ectopic expression of Antp or AbdA transforms the T1 segment toward a T2 (T1 $\rightarrow$ T2) or an A2 (T1 $\rightarrow$ A2) fate, respectively. (A) Same-magnification representative images of wild-type and transformed Tl segments are shown. (B) When misexpressed in combination, wild-type AbdA dominates over Antp, generating an A2-like epidermal phenotype. AbdA variants (AbdA $\left.{ }^{\text {mut }}\right)$ missing the UR motif $\left(\Delta C^{197}, \Delta^{200-220}\right.$, and $2 \mathrm{~W}^{\mathrm{Ala}} \Delta^{200-220}$ ) resulted in T2-like phenotypes, suggesting that they were unable to overcome the activity of Antp. No such defect in dominance was observed when only the YPWM and TDWM motifs were mutated $\left(2 \mathrm{~W}^{\mathrm{Ala}}\right)$, suggesting that the UR motif is used by AbdA to dominate over Antp as well as Scr. The percentages of T1 $\rightarrow$ A2 cuticles are normalized by the fraction of AbdA-containing embryos, according to the specific genotypes (see the Materials and Methods).

variants in developing embryos. AbdA variants were cloned into p131, and transgenic lines were generated using standard P-element transformation (Abu-Shaar and Mann 1998). Lines were selected for similar expression levels by Western blot (mouse anti-Myc 1:1000) (Supplemental Fig. 2). The ubiquitous driver AG11GAL4 was used for all assays. Crosses were grown at $28^{\circ} \mathrm{C}$. Embryos were collected every $12 \mathrm{~h}$ and fixed as previously described (Noro et al. 2006). fkh250-lacZ and fkh250 ${ }^{C O N}-1 a c Z$ on the third chromosome were used (Ryoo and Mann 1999). Flip-out clones were generated by crossing $h s-f l p ; a c t<y<G a l 4$, UAS-GFP to different UAS6xMyc-AbdA lines and heat-shocking larvae for $10 \mathrm{~min}$ at $37^{\circ} \mathrm{C}$. Wing discs were dissected at the wandering stage.

\section{Cuticle preparation}

Cuticle preparations were performed as described in Wieschaus and Nusslein-Volhard (1986). AbdA variants and Antp were ubiquitously expressed using AG11GAL4, and crosses were grown at $28^{\circ} \mathrm{C}$. Homeotic transformations were scored as either "AbdA-like" (head and thoracic segments transformed toward an A2 pattern) or "Antp-like" (head and T1 segments transformed toward a T2 identity). The percentages of $\mathrm{T} 1 \rightarrow \mathrm{A} 2$ cuticles are given as the number of embryos with A2-like transformations over the expected number of embryos misexpressing AbdA, which varies depending on the genotype.

\section{Immunohistochemistry}

Rabbit anti- $\beta$-galactosidase (Cappell, 1:5000), mouse anti-Myc (Santa Cruz Biotechnology, 1:200), and rat anti-HA (Sigma, 1:500) were used for staining embryos as previously described (Noro et al. 2006). Anti-spalt (rabbit 1:500) (Xie et al. 2007) was used for imaginal disc immunostaining. The secondary antibodies used were AlexaFluor488 (1:500), AlexaFluor555 (1:1000), and AlexaFluor647 (1:500) conjugates from Molecular Probes, and embryos were mounted in VectaShield medium. Z-series were collected on a Leica SP5 confocal microscope. All embryonic images shown are Z-projections of the acquired Z-series.
Protein purification and electrophoretic mobility shift assays (EMSAs)

EMSAs were carried out as previously described (Gebelein et al. 2002). The wild-type AbdA construct includes the residues from Ser 79 to the end of the protein (Ryoo and Mann 1999). Schematics of the AbdA mutants used can be found in Figure 2. A nearly full-length wild-type Scr (residues 2-406) (Joshi et al. 2007) was used for the EMSAs in Figure 1. Since regulation of fkh250-lacZ depends on the presence of the HM domain of $\mathrm{Hth}\left(\mathrm{Hth}^{\mathrm{HM}}\right)$ to shuttle Exd into the nucleus but does not require the $\mathrm{Hth}$ homeodomain (Abu-Shaar et al. 1999; Noro et al. 2006; Stevens and Mann 2007), Exd-Hth ${ }^{\mathrm{HM}}$ heterodimers were coexpressed and purified from Escherichia coli and used for all of the EMSAs. Hox proteins and Exd$\mathrm{Hth}^{\mathrm{HM}}$ were purified as His-tagged fusion proteins using Ni chromatography (Gebelein et al. 2002). Protein concentrations were determined by the Bradford assay and then confirmed by SDS-PAGE and Blue Coomassie analysis (GelCode Blue, Pierce). For EMSAs, the following amounts of proteins were used: Exd- $\mathrm{Hth}^{\mathrm{HM}} 50 \mathrm{ng}$ per lane and AbdA 15 and $45 \mathrm{ng}$ per lane. All of the AbdA variants were used in equimolar amounts. The $f k h 250^{C O N}$ probe was previously described (Ryoo and Mann 1999).

\section{Acknowledgments}

We thank Tiffany Cook for the anti-spalt antibody, and members of the Mann laboratory and Brian Gebelein for suggestions. This work was supported by NIH grants GM54510 to R.S.M. and 5T32DK07328 to K.L.

\section{References}

Abu-Shaar M, Mann RS. 1998. Generation of multiple antagonistic domains along the proximodistal axis during Drosophila leg development. Development 125: 3821-3830.

Abu-Shaar M, Ryoo HD, Mann RS. 1999. Control of the nuclear localization of Extradenticle by competing nuclear import and export signals. Genes Dev 13: 935-945.

Bachiller D, Macias A, Duboule D, Morata G. 1994. Conservation of a functional hierarchy between mammalian and insect Hox/HOM genes. EMBO / 13: 1930-1941.

Bender W. 2008. MicroRNAs in the Drosophila bithorax complex. Genes Dev 22: 14-19.

Brand AH, Perrimon N. 1993. Targeted gene expression as a means of altering cell fates and generating dominant phenotypes. Development 118: $401-415$.

Carroll SB, Laymon RA, McCutcheon MA, Riley PD, Scott MP. 1986. The localization and regulation of Antennapedia protein expression in Drosophila embryos. Cell 47: 113-122.

Chopra VS, Mishra RK. 2006. 'Mir'acles in hox gene regulation. Bioessays 28: 445-448.

Dasen JS, Jessell TM. 2009. Hox networks and the origins of motor neuron diversity. Curr Top Dev Biol 88: 169-200.

Duboule D, Morata G. 1994. Colinearity and functional hierarchy among genes of the homeotic complexes. Trends Genet 10: 358-364.

Ernst P, Mabon M, Davidson AJ, Zon LI, Korsmeyer SJ. 2004. An Mlldependent Hox program drives hematopoietic progenitor expansion. Curr Biol 14: 2063-2069.

Galant R, Walsh CM, Carroll SB. 2002. Hox repression of a target gene: Extradenticle-independent, additive action through multiple monomer binding sites. Development 129: 3115-3126.

Gebelein B, Culi J, Ryoo HD, Zhang W, Mann RS. 2002. Specificity of Distalless repression and limb primordia development by abdominal Hox proteins. Dev Cell 3: 487-498.

Gibson G, Schier A, LeMotte P, Gehring WJ. 1990. The specificities of Sex combs reduced and Antennapedia are defined by a distinct portion of each protein that includes the homeodomain. Cell 62: 1087-1103.

Gonzalez-Reyes A, Morata G. 1990. The developmental effect of overexpressing a Ubx product in Drosophila embryos is dependent on its interactions with other homeotic products. Cell 61: 515-522.

Gonzalez-Reyes A, Morata G. 1991. Organization of the Drosophila head as revealed by the ectopic expression of the Ultrabithorax product. Development 113: 1459-1471.

Gonzalez-Reyes A, Urquia N, Gehring WJ, Struhl G, Morata G. 1990. Are cross-regulatory interactions between homoeotic genes functionally significant? Nature 344: 78-80. 


\section{Noro et al.}

Hafen E, Levine M, Gehring WJ. 1984. Regulation of Antennapedia transcript distribution by the bithorax complex in Drosophila. Nature 307: 287-289.

Harding K, Wedeen C, McGinnis W, Levine M. 1985. Spatially regulated expression of homeotic genes in Drosophila. Science 229: 1236-1242.

Hughes CL, Kaufman TC. 2002. Hox genes and the evolution of the arthropod body plan. Evol Dev 4: 459-499.

Jegalian BG, De Robertis EM. 1992. Homeotic transformations in the mouse induced by overexpression of a human Hox3.3 transgene. Cell 71: 901-910.

Joshi R, Passner JM, Rohs R, Jain R, Sosinsky A, Crickmore MA, Jacob V, Aggarwal AK, Honig B, Mann RS. 2007. Functional specificity of a Hox protein mediated by the recognition of minor groove structure. Cell 131: 530-543.

Joshi R, Sun L, Mann R. 2010. Dissecting the functional specificities of two Hox proteins. Genes Dev 24: 1533-1545.

Kuziora MA, McGinnis W. 1988. Autoregulation of a Drosophila homeotic selector gene. Cell 55: 477-485.

Mann RS, Hogness DS. 1990. Functional dissection of Ultrabithorax proteins in D. melanogaster. Cell 60: 597-610.

Mann RS, Lelli KM, Joshi R. 2009. Hox specificity unique roles for cofactors and collaborators. Curr Top Dev Biol 88: 63-101.

Merabet S, Kambris Z, Capovilla M, Berenger H, Pradel J, Graba Y. 2003. The hexapeptide and linker regions of the AbdA Hox protein regulate its activating and repressive functions. Dev Cell 4: 761-768.

Merabet S, Saadaoui M, Sambrani N, Hudry B, Pradel J, Affolter M, Graba Y. 2007. A unique Extradenticle recruitment mode in the Drosophila Hox protein Ultrabithorax. Proc Natl Acad Sci 104: 16946-16951.

Moens CB, Selleri L. 2006. Hox cofactors in vertebrate development. Dev Biol 291: 193-206.

Noro B, Culi J, McKay DJ, Zhang W, Mann RS. 2006. Distinct functions of homeodomain-containing and homeodomain-less isoforms encoded by homothorax. Genes Dev 20: 1636-1650.

Ronshaugen M, Biemar F, Piel J, Levine M, Lai EC. 2005. The Drosophila microRNA iab-4 causes a dominant homeotic transformation of halteres to wings. Genes Dev 19: 2947-2952.

Ryoo HD, Mann RS. 1999. The control of trunk Hox specificity and activity by Extradenticle. Genes Dev 13: 1704-1716.

Saadaoui M, Merabet S, Litim-Mecheri I, Arbeille E, Sambrani N, Damen W, Brena C, Pradel J, Graba Y. 2011. Selection of distinct HoxExtradenticle interaction modes fine-tunes Hox protein activity. Proc Natl Acad Sci 108: 2276-2281.

Schneuwly S, Klemenz R, Gehring WJ. 1987. Redesigning the body plan of Drosophila by ectopic expression of the homoeotic gene Antennapedia. Nature 325: 816-818.

Singh NP, Mishra RK. 2008. A double-edged sword to force posterior dominance of Hox genes. Bioessays 30: 1058-1061.

Stevens KE, Mann RS. 2007. A balance between two nuclear localization sequences and a nuclear export sequence governs extradenticle subcellular localization. Genetics 175: 1625-1636.

Struhl G. 1983. Role of the $\mathrm{esc}^{+}$gene product in ensuring the selective expression of segment-specific homeotic genes in Drosophila. I Embryol Exp Morphol 76: 297-331.

Struhl G, White RA. 1985. Regulation of the Ultrabithorax gene of Drosophila by other bithorax complex genes. Cell 43: 507-519.

Wieschaus E, Nusslein-Volhard C. 1986. Looking at embryos. IRL Press Limited, Oxford.

Xie B, Charlton-Perkins M, McDonald E, Gebelein B, Cook T. 2007. Senseless functions as a molecular switch for color photoreceptor differentiation in Drosophila. Development 134: 4243-4253.

Yekta S, Tabin CJ, Bartel DP. 2008. MicroRNAs in the Hox network: An apparent link to posterior prevalence. Nat Rev Genet 9: 789-796. 


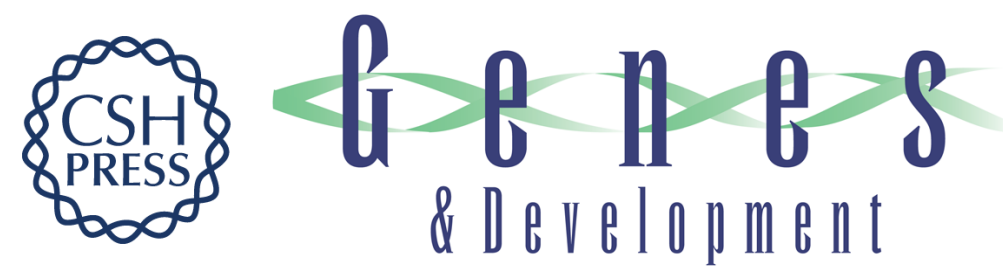

\section{Competition for cofactor-dependent DNA binding underlies Hox phenotypic suppression}

Barbara Noro, Katherine Lelli, Liping Sun, et al.

Genes Dev. 2011, 25:

Access the most recent version at doi:10.1101/gad.175539.111

Supplemental http://genesdev.cshlp.org/content/suppl/2011/11/11/25.22.2327.DC1
Material

References This article cites 39 articles, 14 of which can be accessed free at:

http://genesdev.cshlp.org/content/25/22/2327.full.html\#ref-list-1

License

Email Alerting

Receive free email alerts when new articles cite this article - sign up in the box at the top

Service

right corner of the article or click here.

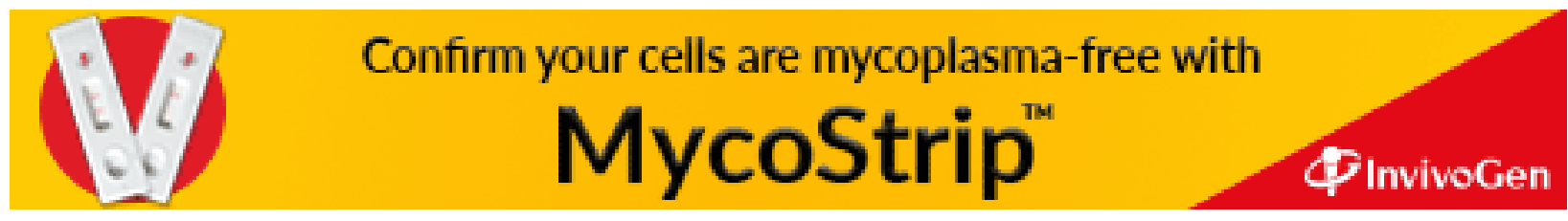

